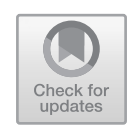

\title{
Mobility, Power and International Mental Health
}

In 1960, seventeen newly independent countries, most of them African, became formal member states of the United Nations (UN). This number grew over the next decade, with Uganda's application ratified in 1962, so that by 1970 the decolonising world was the dominant power within the UN. This shift in the balance of power would significantly alter debates and policy formation from the 1960s, not least within the World Health Organization (WHO), which now had to contend with the demands of new member states for economic development. ${ }^{1}$ Addressing the World Federation of Mental Health (WFMH) in 1961, Maria Pfister, Medical Officer in the Mental Health Section of the WHO, described how 'the dynamic characteristics' of the shift in membership 'is felt throughout the Organization, and the rapidly increasing number of countries gaining independence has led to a corresponding increase in the number of health programmes being planned and set up in conjunction with WHO', especially in Africa. ${ }^{2}$ In addition to responding to requests for emergency assistance, the $\mathrm{WHO}$ was setting up long-term training programmes in a range of health-related subjects in developing countries, seeking new collaborative research links and broadening the membership of its Expert Advisory Committees. ${ }^{3}$ In 1961, the Eleventh Expert Committee on Mental Health, which discussed the role of public health officers and general practitioners in mental health care, comprised eight psychiatrists from around the world, including Thomas Adeoye Lambo (Nigeria), Jose Horwitz (Chile) and W. A. Karunaratne

(C) The Author(s) 2019

Y. Pringle, Psychiatry and Decolonisation in Uganda, Mental Health in Historical Perspective, https://doi.org/10.1057/978-1-137-60095-0_6 
(Ceylon). ${ }^{4}$ The following year, among the seven psychiatrists attending the Twelfth Expert Committee on Mental Health, which looked at the training of psychiatrists, were Taha A. Baasher (Khartoum), Tsung-yi Lin (Taiwan) and Ignacio Matte Blanco (Chile). ${ }^{5}$ While during the early 1960s, as Pfister herself stressed to the WFMH, the WHO made no explicit distinction between developed and developing countries in their mental health policy, this changed over the next decade. The rise of a New International Economic Order within the UN General Assembly, focused on promoting economic and social development in developing countries, found expression within the WHO in calls to address systemic disparities in health between developed and developing countries. ${ }^{6}$

This emergent language of global structural inequality, as well as 'developing countries' as a distinct bloc with its own challenges and needs, pervaded the Sixteenth Expert Committee on Mental Health, which considered the organisation of mental health services in developing countries. Meeting in 1974, the Committee stressed that over forty million men, women and children were suffering from 'serious untreated mental disorders' in developing countries, and that mental health could not be considered in isolation from social and economic development. ' 'In planning services', according to Norman Sartorius, a Croatian psychiatrist and Chief Medical Officer of the WHO's Office of Mental Health, 'standards from countries in the United States and Europe are often taken as the objective to be reached, although both planners and psychiatrists fully realize the impossibility of reaching it; what is worse is that even if these objectives should be achieved, it is questionable whether they would lead to optimal service delivery patterns' ${ }^{8}$ In line with the new political climate, it was increasingly argued that developing countries needed to define their own needs and objectives, taking into account what was possible in the short term in poor socio-economic settings. This context-specific approach to policy marked a departure from the WHO's more usual technocratic approach, in which the systematic collection and comparison of information was used to define universal norms and standards. While psychiatrists in countries around the world had increasingly experimented with mental health care and the extension of psychiatry beyond institutions since the late 1950s, by 1974 the WHO had not yet attempted methodologically rigorous research on the organisation and effectiveness of these new approaches. Despite this, the WHO sought to provide strategic guidance on how psychiatry and mental health care in developing countries might best be 
developed. The Report of the Expert Committee, published in 1975, recommended that member states in developing countries should move to decentralise mental health services, integrate mental health care with general health services, and allow for the sharing of mental health tasks between psychiatrists, a wide range of health workers, and community agencies. ${ }^{9}$ This broadly-conceived version of mental health in primary care would become the major plank of WHO policy on mental health over the next three decades.

This chapter explores the ways that psychiatrists-particularly African psychiatrists-mobilised and shared ideas on strategies for improving mental health care from the early 1960s. It does so in order to trace the roots of the WHO's policy of mental health in primary care. Uganda was one of a range of countries whose model of training and delegating responsibility to a range of health care workers attracted the interest of staff attached to the WHO's Office of Mental Health. Temporally, this chapter overlaps with the reforms within Uganda discussed in Chapter 5, but instead explores how ideas about the organisation of mental health care, and what this might mean for the future of psychiatry as a profession, were discussed in an increasingly focused manner at regional and international meetings through the 1960s. The psychiatrists explored in Chapter 5 never intended their activities to remain limited to the local or national context, but sought to inform a more contextually sensitive psychiatry elsewhere. The discussions held among psychiatrists from across Africa highlight the variety of models still being explored in national contexts by the early 1970s, disagreements about the extent to which psychiatry could be delegated to others and shared concerns about the social and cultural gulf between psychiatrists and their patients. At the same time, they also raise questions about mobility and the power of psychiatrists, either individually, or as a group of 'African psychiatrists' or psychiatrists from 'developing countries'. And they can help us understand why some countries (or indeed individual psychiatrists) were more dominant than others. The capacity of psychiatrists to contribute both to an increasingly transnational and global body of ideas about mental health care was shaped by a wide range of factors, not least political stability, the availability of funding, and sufficient manpower within their own countries to allow psychiatrists to travel and participate in international mental health. This was no less the case in Uganda as it was elsewhere. The opening of the Department of Psychiatry in 1966 not only increased the number of psychiatrists able to experiment with mental 
health care, but allowed professional freedom and the financial means (if still limited) to travel, particularly among those whose contracts included research. The political and economic turmoil that followed Idi Amin's takeover of the country in January 1971, however, and the conflict and violence that continued into the 1980s, saw most of the expatriate psychiatrists leave the country, and Ugandan psychiatrists flee into exile. After 1973, Uganda's role in international mental health was limited to those psychiatrists now in the diaspora.

\section{The Making of an 'African' Psychiatric Tradition}

The professionalisation of psychiatry in Africa coincided with decolonisation and increased interest in the mental health problems of the rapidly decolonising world within international mental health. In this context, it was politically important to many of those attending the first international meetings on psychiatry and mental illness in Africa to push back against the biodeterminism that had been espoused by ethnopsychiatry and to demonstrate the universality of the human psyche. The first major 'Meeting of Specialists on Mental Health' in Africa, held in Bukavu in March 1958 under the auspices of the Commission for Technical Co-operation in Africa South of the Sahara (CCTA), the WFMH and the WHO, concluded that psychiatrists should aspire to global uniformity in their ideas about and responses to mental illness. While attention should be given to 'the particular ethnic, cultural and social conditions prevailing in this continent', the final report noted, psychiatric approaches should be broadly the same as in other continents. ${ }^{10}$ Notions of equality and unity were also at the forefront of the First Pan-African Psychiatric Conference, organised by Thomas A. Lambo in Nigeria in November 1961, just one year after Nigerian Independence. In using the conference to emphasise the 'unity of mankind', Lambo, to borrow a phrase from Matthew Heaton, was attempting 'to insert cultural politics into a psychiatric framework'. ${ }^{11}$

The politically conscious nature of these early meetings of psychiatrists made many feel uneasy about the unequal distribution of the participants. Of the thirty-four delegates attending the meeting in Bukavu, only twelve were psychiatric professionals practising in Africa and, with the exceptions of Tigani el Mahi (Sudan), E. B. Forster (Ghana), A. C. Raman (Mauritius) and Abraham Ordia (Nigeria), all were expatriates. G. I. Tewfik attended as representative for Uganda, and had to confess 
to the group that he had 'so little personal experience' that he could only review the literature on psychosis in Africa, drawing heavily on J. C. Carothers' monograph The African Mind in Health and Disease, rather than presenting a context-specific analysis of Uganda. ${ }^{12}$ Three years later, in Nigeria, Lambo attempted to rectify the situation somewhat, bringing together ninety-two participants from twenty-two countries in Africa, Europe and the USA. These included major figures in transcultural psychiatry, such as Alexander H. Leighton and Sir Aubrey Lewis, the founder of the WFMH, John R. Rees, and E. E. Krapf, Chief Medical Officer of Mental Health at the WHO. Forster and El-Mahi were also in attendance, as well as T. W. Murray, as representative for Uganda. ${ }^{13}$ Yet psychiatrists working in Africa were again outnumbered at the conference, leading to frustration, among some, that international delegates were 'Inexperienced in the sense that their view of African problems was rarely based on the reality of the African situation, and tended to be heavily influenced by theoretical formulations and current Western attitudes and ideologies concerning developing countries and "primitive" societies' 14

At the end of the First Pan-African Psychiatric Conference, Lambo called for the creation of a professional association 'meant entirely for psychiatrists working in Africa; actively engaged in some form of mental health work in Africa, irrespective of their origin or nationalities' ${ }^{15}$ In order to be in a position to ensure that discussion of mental illness in Africa was focused on practical realities, psychiatrists needed to engage in close collaboration with colleagues from across the continent. The proposal represented a call to decolonise psychiatric practices as well as an appeal to a sense of common challenges facing psychiatrists working in Africa. This included professional isolation (both from other branches of medicine and from other psychiatrists), ongoing underdevelopment and neglect by national governments, and the social and cultural gap between psychiatrists and their patients-a gap that had not been resolved through Africanisation. It was this sense of shared experience, more than any appeal to African unity, that provided a common starting point for psychiatrists in Africa, and which required an inclusive approach to membership.

Despite agreement as to the need for a professional body of psychiatrists in Africa, the establishment of an association proved impractical in 1961 due to the size of the continent and a lack of funds for regular meetings. While international organisations like the WHO and the 
WFMH were increasingly making small sums available to assist with conference organisation, attendance and training, a long-term commitment for an association was not forthcoming. Instead, eight psychiatrists, including Lambo, Tolani Asuni (Nigeria), Henri Collomb (Senegal) and Raman, agreed to create 'a feeling of association' through correspondence and an agreement to organise a conference every five years. Overall, the correspondence system was not a success, with workloads preventing regular correspondence between most. ${ }^{16}$ One exception appears to have been between G. Allen German, of Makerere University College, Uganda, and Asuni, whose brief visit to Uganda in 1967 was unexpectedly extended by a short period when the outbreak of the NigerianBiafran war prevented his return home. According to German, a warm friendship was sparked between the two and, having discovered common psychiatric viewpoints, an active correspondence ensued. ${ }^{17}$

The situation was different when the idea of an association was again raised in the late 1960s: not only had the number of psychiatrists in Africa increased significantly (in relative terms, at least), but international organisations were investing more in mental health. Following further discussions at the Second Pan-African Psychiatric Conference in Dakar, Senegal, in 1968, the Association of Psychiatrists in Africa was eventually launched at the workshop on 'Mental Health Services in Developing Countries' in Kampala in April 1969, with Asuni elected as its first President. The workshop was recognised as a fitting venue for the official launch of the Association because it was the first meeting on the continent at which psychiatrists working in Africa were in the majority. Generous funding from the Commonwealth Foundation meant that twenty-two of the twenty-nine delegates were from Africa, with representatives from Ghana, Kenya, Nigeria, Sudan, Ethiopia, Zambia, Tanzania and Mauritius. Seven psychiatrists in Uganda, including Stephen B. Bosa, unable to attend other meetings due to a flying phobia, were also in attendance. ${ }^{18}$ The composition therefore fit with the Association's aim of taking 'the lead in promoting developments in psychiatry within Africa and in speaking to the outside world with a relatively united voice'. ${ }^{19}$ While all were broadly in agreement that transcultural psychiatric research had so far demonstrated the universality of mental illness and the human psyche, there remained debate over the future of psychiatry in Africa, and the extent to which social, cultural and economic circumstances demanded that psychiatry be different to that elsewhere. 
The discussion at the workshop highlighted a wide variety of experiments in new ways of providing mental health care already underway. These included village settlements in Tanzania and Nigeria, which raised concerns among delegates about cost, staffing and stigma. ${ }^{20}$ Baasher offered a 'striking example' of his own practice in Sudan, where he described rejecting the mental hospital 'on the grounds of distance and divorce from local culture'. ${ }^{21}$ Instead, he had asked for beds in district hospitals, drawing on the additional support of traditional healers and prison authorities in what could be termed 'a spread-out mental hospital'. ${ }^{22} \mathrm{H}$. G. Egdell described the development of new psychiatric units in remote rural hospitals in Uganda, staffed by a new grade of medical assistant who was 'the key one in the development of rural psychiatric services'. ${ }^{23}$ Several others, meanwhile, remained enthusiastic about the ongoing importance of large mental hospitals, emphasising their complexity and 'necessity for good record keeping'. ${ }^{24}$ Yet while all were dealing with similar legacies stemming from colonial rule, there was no clear consensus on how mental health care might be best reorganised. There was broad agreement about the need for more support for psychiatrists, in some form or another, deemed essential to extending the reach of psychiatry given the lack of specialist personnel and limited resources. Yet the definition, training, and responsibility of these additional workers remained a matter of contention. While Charles R. Swift, psychiatrist in Tanzania, defined the auxiliary as 'someone who helps a member of the psychiatric team', Egdell pushed for a more specialist understanding, with responsibilities to assist general medical officers, assist the psychiatrist and 'trained to take on a certain amount of responsibility to provide continuity of care, and even leadership in times of crisis'. ${ }^{25}$ Stressing the linguistic and cultural problems of understanding patients, Mrs. A. P. White, a sociologist and research assistant with the Department of Psychiatry, suggested the development of a new grade of auxiliary, 'the patient's friend', someone with only very basic training in psychiatry, 'to whom the patient would be assigned following his initial contact with the doctor and who would act as an intermediary'. ${ }^{26}$ Meanwhile, J. W. S. Kasirye, Medical Superintendent of Butabika Hospital, added that he believed there was scope for health visitors to be used as "case "spotters", but he did not think that they, 'as medical assistants, could undertake a therapeutic role'. ${ }^{27}$

Underlying these disagreements were concerns both about the ability of auxiliaries to care for patients with major mental illness and justifiable fears about psychiatrists' hard-won, but still insecure professional status 
within their home countries. Changes in the organisation and delivery of mental health care had implications for the nature of psychiatric practice, with more time spent supervising and training health workers, social workers and other related professionals. Such concerns over status were not limited to psychiatrists in Africa. In debates on mental health care in Asia, too, were concerns that while additional manpower was necessary, particularly among nurses and auxiliaries, psychiatrists needed to work to overcome any 'demarcation disputes'. As Carstairs noted on India, what psychiatrist would really want to work in a supervisory role in an up-country clinic? In a statement that recalls the use of remote postings as a punishment for dissent under colonial rule, he added: 'Young doctors all aspire to work in towns, either in large well-equipped hospitals or in lucrative private practice'. ${ }^{28}$

Disagreements over the use of psychiatric auxiliaries reflected broader uncertainty about the role psychiatrists should have in Africa, and the workshop and Association provided the first opportunity for collective discussion on what the role of the psychiatrist in Africa might be. On this question, some were uneasy about taking on too much responsibility beyond that which they had been trained. Adomakoh 'cautioned the psychiatrists against accepting too wide a social advisory role because of their over intense need to please'. ${ }^{29}$ A. Boroffka, meanwhile, argued that while health promotion and the advising of educationists, economists and town planners were 'fascinating and attractive', and psychiatrists should prepare themselves for those tasks, for the time being they should be modest in their outlook. As there were so few psychiatrists in Africa, an advisory role 'borders on betrayal of our professional ethics.... One also may loose [sic.] one's expertness in psychiatry if one stops seeing patients'.$^{30}$ Others at the meeting disagreed, arguing that 'the psychiatrist could not be so confined, particularly in a developing society where his intelligence and expertise are at a premium. He must be prepared to take on many mantles, and must be prepared to offer advice in those areas of social planning which were likely to influence the mental health and happiness of people'. ${ }^{31}$ Whatever individual psychiatrists might see their roles as being, however, they were likely to come up against resistance from administrators and other leaders, their being 'slow to recognise more than a custodial and curative role for mental health experts'. ${ }^{32}$ The question of what 'African' psychiatry should be was not resolved here, and nor did the delegates necessarily believe that it should be. Despite their common challenges, they recognised the vast differences 
that existed not only between countries but within them. More important, was a common sense that creativity was necessary-what Diop later explained to the African Regional Committee of the WHO as the need for flexibility in the reorganisation of existing mental health services, and for countries to 'innovate according to their circumstances and the requirements of community psychiatry'. ${ }^{33}$ It was this need for innovation and for the involvement of psychiatric auxiliaries that WHO officials would find most appealing in debates about the future of mental health care.

\section{The WhO and Mental Health in Primary Care}

In the decades following the Second World War, the WHO, the WFMH, and the Commonwealth Foundation provided funding that enabled psychiatrists in developing countries to participate in international mental health. These most frequently took the form of small regional meetings, involving less travel, fewer costs and allowing closer dialogue between people who shared similar professional and socio-cultural conditions. They provided spaces for the sharing of ideas, the establishment of general principles and practical strategies for raising psychiatry and mental health as a priority among national planners. As Senegalese psychiatrist S. M. B. Babakar Diop stressed in 1973, 'everything may seem to have priority when it is a question of establishing a nation, uniting a country', and ensuring that everyone had access to food, education, medical care and work. ${ }^{34}$ These meetings did not achieve, or even aim at identifying uniformity in approaches to psychiatry and mental health care, however. Just as delegates at the workshop in Kampala in 1969 highlighted the range of approaches required to account for the wide variation in geographical, social, cultural and economic conditions, so did those at a conference on the organisation of mental health services in India in 1971. Organised by the Indian Psychiatric Association and sponsored by the WFMH, the final report stressed that because of this diversity, there was not only 'an opportunity' but 'a need to experiment with different methods of delivering mental health care' ${ }^{35}$

While the WHO facilitated these discussions by helping to organise meetings throughout the 1960s, it was not until the early 1970s that the WHO's Office of Mental Health, as represented by Sartorius, Harding and Joy Moser, started to outline priorities for the development of mental health services in developing countries. These included the need to 
establish what types of mental illness were suitable for intervention on a wide scale, what innovations in mental health care were already underway in member states, and the development of pilot programmes to test and evaluate the operation of these strategies. Above all, was a concern to promote the 'development of front-line mental health manpower to meet the needs of local areas, and collaboration with existing health services'. ${ }^{36}$ This was in line both with the WHO's own priorities as a public health organisation and with the approaches being trialled in contexts around the world. Harding referred to the success of 'innovative efforts' to train and 'include in the care of the mentally ill those who previously had no mental health function'. He cited programmes for the training of assistants in Uganda, Zambia, and Sarawak, public health nurses in Colombia, and traditional healers and the wider community at Aro, Nigeria, under Lambo. ${ }^{37}$ Moser similarly reported on Tanzanian medical auxiliaries who had received a week's intensive training, a programme to train Zambian psychiatric medical assistants ('mini-psychiatrists'), and schemes in Uganda to train medical assistants who could assist in district hospitals and who were 'trained to take on a certain amount of responsibility for continuity of care, and even leadership in times of crisis' ${ }^{38}$

Many of the experiments in reorganising mental health care resonated with the WHO officials because they presupposed an integrated approach to public and mental health. In the context of broader calls within the UN for social and economic development in developing countries, the need for a strategy for mental health care had taken on a new urgency, and the experiences of psychiatrists in developing countries provided a body of practical examples as to how this might be achieved. Mental health was already being overlooked in the high-level intra-agency meetings between the World Health Assembly and the UNICEF/WHO Joint Committee on Health Policy (JCHP) on primary health care which would culminate in the 1978 Alma-Ata Declaration, and clear policy was needed. As Harding summarised in the opening statements to the WHO Seminar on the Organization of Mental Health Services in Addis Ababa, 1973, there was 'a need to be much more specific than in the past in defining mental health services'. Instead of 'imprecise requests for services described with a blanket reference to "mental health" or "psychiatry", psychiatrists needed to be prepared to make their case with reference to financial implications, target populations, personnel management and potential health outcomes. So too should psychiatrists be wary of proposing too many changes at once. As 
Harding cautioned, 'The risk is that this becomes a shopping list presented to the health planner whose first thought will be the enormous expense of such a "comprehensive" service. The temptation will be to provide little or nothing'. ${ }^{39}$

From 1973, Sartorius, Harding and Moser consulted widely with psychiatrists from around the world. With the express intention of drawing up suggestions for $\mathrm{WHO}$ action, Moser toured nine African countries in late 1973, attending a meeting of the Association of Psychiatrists in Africa in Lagos, Nigeria, at which the Association provided a unified position on the importance of psychiatric auxiliaries in mental health care in Africa. She also attended the WHO Africa Regional Committee, also in Nigeria, whose technical discussion was on the place of mental health in public health. ${ }^{40}$ Harding, meanwhile, attended a seminar on the organisation of mental health services held under the auspices of the WHO's Regional Office for the Eastern Mediterranean in Addis Ababa in November-December 1973, and whose participants included Narendra N. Wig (India), Collomb, Asuni, Ravi L. Kapur (India) and A. Kamal (Iraq). Harding's attendance and introductory paper presented at the meeting was explicitly intended 'to draw together some of the key issues which face WHO (including its Expert Committee) as well as governments and individuals who are concerned with the problems of mental health in the developing countries'. ${ }^{41}$ Sartorius, moreover, attended an Association of Psychiatrists in Africa workshop in Nairobi in September 1974, one month before the Expert Meeting on the Organisation of Mental Health Services in Developing Countries. One afternoon, German recalled, he was invited to join Sartorius and other WHO colleagues to discuss the methods used to extend the reach of psychiatry in Uganda, and the strategies employed where specialist personnel were scarce. ${ }^{42}$ Such discussions would only have reinforced existing sentiment that the lack of psychiatrists meant that the extension of mental health services required the use of new types of personnel as well as a reorientation of the relationship between psychiatry and other institutions and services.

The Sixteenth Expert Committee on Mental Health met in Geneva in October 1974, bringing together ten expert members, including Wig, Diop, F. Workneh (Ethiopia), M. A. Bakiri (Algeria), E.-S. Tan (Malaysia) and C. A. Leon (Colombia). Taiwanese psychiatrist T.-Y. Lin was in attendance as the representative of the WFMH, and among the Secretariat were Baasher, Binitie, and Sartorius, Moser, 
and Harding. Over seven days, the participants discussed the extent and nature of mental health problems in developing countries, present responses, different approaches to the development of services, manpower, monitoring and evaluation, regional and international activities and drafted and finalised a final report. ${ }^{43}$ Introduced by Lambo in his capacity as Deputy Director-General of the WHO, the Report stressed that the most urgent problem in the development and delivery of mental health services was adequate coverage of the population, particularly in rural areas with a widely dispersed population. The most important constraint, meanwhile, was 'the extreme scarcity of mental health professionals'-less than one per million of the population, in some countries-something that required 'fresh consideration of the role and training both of general health workers and of mental health professionals'. ${ }^{44}$ Denouncing centralised and custodial mental hospitals as inappropriate and counter-therapeutic, the Report unequivocally recommended 'the decentralization of mental health services' to community, regional and district levels, the 'integration of mental health services with the general health service', and 'the development of collaboration with nonmedical community agencies' such as religious leaders, teachers and the police. ${ }^{45}$ While some limited cooperation between health workers at the village level and traditional healers might be useful, or at least not harmful, it steered away from recommending collaboration between traditional healers and psychiatrists, and even suggested that psychiatrists might seek to exercise some form of control over their practices. ${ }^{46}$ Cooperation with those working in general health services, instead, would be the priority. In consequence, a major part of the psychiatrists' role in developing countries would involve providing basic training for less specialist personnel, supervision for health workers and limited care for only the most difficult cases. This, according to R. Giel and Harding, was in alignment not only with shifts already underway in many developing countries, but with the redirection of WHO programmes towards the strengthening of basic health services through primary health workers. ${ }^{47}$

The Expert Committee had made its recommendations on the basis of a collected body of knowledge and experience from psychiatrists in developing countries over the previous decade. These had shown that with only minimal financial investment, improved mental health care in developing countries was not an unattainable ideal'. ${ }^{48}$ This approach to policy formation was problematic, however, being in opposition to the 
WHO's preferred technocratic method of systematic research and data collection. Within only a few months of the publication of the Report, concerns started to be raised that there was no evidence that primary health workers could manage major psychiatric illness, and without this they could not persuade political leaders to include it as an approach in national health policy. ${ }^{49}$ It was evidence that could be used for standard- and policy-making that the WHO Collaborative Study on Strategies for Extending Mental Health Care took as its main objective. Starting in 1975, pilot programmes were established in seven countries-Brazil, Colombia, Egypt, India, the Philippines, Senegal and Sudan-to assess the feasibility and effectiveness of different techniques for community-based mental health care, training methods for health workers, and the roles that might be played by those not directly concerned with health, such as the police. ${ }^{50}$ Yet even this proved unsuccessful: a lack of resources and personnel rendered any sophisticated evaluation of these programmes impossible, resulting in a lack of any useful comparable data between them. Despite this, participation in the study alone confirmed to the WHO the value of mental health in primary care. The ability of primary health workers to provide mental health care, it was observed, was serving to change attitudes towards the mentally ill among health personnel, administrators and health planners in the study areas: 'Initial resistance...soon developed into general acceptance of the use of primary health workers' ${ }^{51}$ This ideal of the integration and delegation of mental health would remain pervasive in international mental health policy over the next three decades.

\section{IN THE DIASPORA}

After 1973, Uganda ceased to be a major voice in international mental health. Most of the expatriate and many Ugandan psychiatrists left the country in the wake of Amin's expulsion of the Asian population in 1972. Those who remained did so in increasingly difficult circumstances, with little chance of being granted leave to attend international meetings or conferences. The loss of personnel, combined with political and economic insecurity, sent psychiatry into a long period of stagnation and decline, from which it would only start to recover in the 1990s. This drain on psychiatry in Uganda, however, coincided with the movement of psychiatrists into teaching, research and advisory positions elsewhere in Africa and beyond. Their movement 
highlights the increasing interconnectedness of international mental health, with practical experience-particularly 'on the ground' experience-being highly valued by universities and international organisations such as the WHO.

Those who sought an exit from the uncertainty and instability first of Amin's rule, and then the civil conflict that followed, found themselves in a privileged position compared to many others in Uganda. Following the leads of Uganda, Nigeria and Senegal, medical schools across Africa started investing in psychiatry, creating opportunities for psychiatrists to find work elsewhere. These psychiatrists took with them expertise in training as well as experience in research and public education. Joseph Muhangi, who had been promoted to Associate Professor and Head of the Department of Psychiatry after German's departure in 1972, was among those forced to look for opportunities elsewhere. Originating from Ankole and representing an educated elite, Muhangi was under threat of attack by Amin's forces, and when a new Senior Lectureship in Psychiatry was established at the University of Nairobi in 1975, he fled, taking what was most likely a significant cut in pay. In Nairobi, Muhangi introduced a new research programme in child psychiatry and helped to increase the allocation for psychiatry in the undergraduate medical curriculum from 200 to 300 hours. With his Kenyan colleague W. J. Muya, he drew up suggestions for the revision of the Mental Treatment Ordinance, last updated under colonial rule. With support from the University of Nairobi, Muhangi also continued to attend meetings of the Association of Psychiatrists in Africa, becoming Assistant-Editor-in-Chief of the newly established African Journal of Psychiatry in $1975 .{ }^{52}$ In 1976, Muhangi was then joined by Wilson Acuda, a Ugandan psychiatrist who had been in London studying for the MrcPsych at the time of Amin's coup, and had been unable to return home. By the late 1970s, the increased number of staff at the Department of Psychiatry allowed the University of Nairobi to agree to postgraduate training, with a new MMed in Psychiatry, modelled on the Uganda syllabus. ${ }^{53}$ In 1980, shortly after Amin's overthrow, Muhangi returned to Makerere, restarting the MMed programme and keen to rebuild psychiatry. Yet, like many others, Muhangi lived with 'enormous anger over what Amin had done'. ${ }^{54} \mathrm{He}$ turned to politics, running for and being elected an MP under Milton Obote's new government. A few months later, while travelling with his sons to visit family in Ankole, he was stopped and shot dead in front of his sons 
by anti-Obote guerrillas and left by the side of the road. ${ }^{55}$ Acuda, meanwhile, stayed in Nairobi, becoming Professor and Head of the Department of Psychiatry in 1983. He then moved to Zimbabwe to head up the Department of Psychiatry, and in 1998 returned to the UK to work in the National Health Service (NHS), where he remained until retirement in 2012. ${ }^{56}$

The expatriate psychiatrists who left Uganda were even more mobile. John Cox returned to the UK, where he remained active within the fields of transcultural psychiatry and perinatal psychiatry, becoming Secretary General of the World Psychiatric Association (WPA), 2002-2008. He helped drive the agenda of British transcultural psychiatry on institutional racism, arguing for the dangers of making essentialist assumptions about race, culture and ethnicity in psychiatric training and practice. ${ }^{57}$ Orley returned to the University of Oxford in 1973, before moving to the WHO's Division of Mental Health, Geneva, where he worked between 1983 and 1998, rising to become Programme Manager. In addition to work on all area's of the WHO's mental health programme, Orley was directly involved in formulating policy and guidelines on mental health in primary care, including The Introduction of a Mental Health Component into Primary Health Care (1990), which set out the 'practical steps' by which national governments might reorganise mental health services. He could easily have been speaking of his experience in Uganda when he noted in 1998 that the concept of primary health care arose 'in part as a reaction to the horrific inequalities that exist in medical care, in which a large proportion of the health budget goes towards a few specialist hospitals, usually teaching hospitals' ${ }^{58}$ Wood and German, meanwhile, both moved to Australia to take up positions there. German, from a new position at the University of Western Australia, continued to advise on mental health policy for the WHO Africa Regional Office and Western Pacific Region. ${ }^{59}$ He returned to East Africa on multiple occasions in subsequent decades as a WHO consultant and, like Orley, he contributed to the further formulation of WHO policy on mental health in primary care. His contribution was given special mention in the preface to The Introduction of a Mental Health Component into Primary Health Care (1990). ${ }^{60}$

The global mobility afforded to psychiatry was not limited to psychiatrists, however. Vincent B. Wankiiri, one of the first psychiatric nurses, had observed the changes instituted by psychiatrists at Butabika Hospital, if he was critical of their refusal to embrace cultural ideas 
and practices in treatment. He remained at Butabika through the 1970s but was offered an opportunity to travel by the WHO in the early 1980s as a Psychiatric Nurse Tutor with postings in Lesotho, Botswana and Swaziland as well as short-term training consultancies elsewhere. ${ }^{61}$ Like Uganda's psychiatrists, Wankiiri benefitted from the value placed on practical experience, particularly in guiding national governments towards community and primary health care approaches. In Zimbabwe, he advised on the post-basic Psychiatric Nurse Training Programme, aiming to bring it in line with current psychiatric nursing approaches, including promotional, preventive and therapeutic mental health care within the framework of primary health care' ${ }^{62} \mathrm{He}$ contributed to the WHO Collaborative Study on Strategies for Extending Mental Health Care being carried out in Brazil, Colombia, Egypt, India, the Philippines, Senegal and Sudan and was a participating investigator for the WHO's Diagnostic and Management Guidelines for Mental Disorders in Primary Care (ICD-10 Chapter V, Primary Care Version) (1996). ${ }^{63}$

Despite having complained about the lack of priority accorded to psychiatry in Uganda, Wankiiri recalled how it was completely different in these countries: 'they didn't have anything, they didn't have any psychiatrists', and where they did, they were of the 'old custodial care' kind, 'and that's what I tried to break down by training nurses' ${ }^{64}$ His were community mental health nurses, what he described as 'the modern care of psychiatric patients', and for whom Wankiiri helped develop flow-charts for the identification and management of different mental health problems. ${ }^{65} \mathrm{He}$ believed there could, and should, be an 'African' model for mental health training, in which ideas of 'community' were key, and where the only way to secure 'Health for All' was through collaboration between 'modern mental health care workers' and 'traditional practitioners'. ${ }^{66}$ Yet he encountered 'widespread negative attitudes' to the use of community mental health nurses among key people, including, in Lesotho, 'some influential doctors at district hospitals' who were themselves in charge of mental health units. ${ }^{67}$ Those providing care to the mentally ill were still regarded 'as custodians of "mad people" and some nurse managers preferred their nurses to spend time providing general nursing care in hospitals, 'rather than pay consultative visits to rural health centres or visit patients' families' ${ }^{68}$ Wankiiri would spend the rest of his career attempting to advocate for what he deemed to be a more African-centric approach to mental health care. 


\section{CONCLUSION}

From the early 1980s, mental health in primary care became a major plank of WHO policy on mental health. It remained in the shadow of the WHO's broader policy on primary health care, however. Despite the determination of WHO staff to raise of the profile of mental health during the early 1970s, it did not feature significantly in the WHO's 'Health for All by the Year 2000' resolution of 1977 or at the AlmaAta International Conference on Primary Health Care in 1978. Hailed as 'a victory for international health at the community level', ${ }^{69}$ the Declaration of Alma-Ata, which was signed by 175 countries, defined primary health care as 'essential health care based on practical, scientifically sound and socially acceptable methods and technology made universally accessible to individuals and families in the community through their full participation and at a cost that the community and country can afford to maintain at every stage of their development in the spirit of self-reliance and self-determination'. ${ }^{70}$ It was to be an integral part of the national health system, aiming to bring 'health care as close as possible to where people live and work'. ${ }^{71}$ Mental health was discussed at Alma-Ata but, significantly, was not included in the final declaration. This oversight had serious implications for those seeking funding for mental health programmes, and meant that not all countries included mental health within their definitions of primary health care in the years following the conference-Uganda included. ${ }^{72}$ Only since the late 1990s, when the Uganda Government recognised an increase in mental health problems, has the Ministry of Health looked at ways to integrate mental health into primary health care through its National Mental Health Care Package. It remains a central irony within psychiatry in Uganda that it has needed to seek WHO advice on an approach that Uganda helped pioneer. ${ }^{73}$

The role of psychiatrists working in Africa during the late 1960s and early 1970s in shaping international mental health policy highlights the power of collective experience and shared knowledge during this moment of increased mobility and attention on the health problems of developing countries. While psychiatrists recognised variations in political, social, economic and cultural conditions, both within and between countries, they also saw common challenges and problems that required experimentation with such approaches as the use of psychiatric auxiliaries, group therapy, village settlements and rural 
psychiatric outpatient clinics. This was a period of innovation in mental health care across many developing countries, in which the WHO then sought out their guiding role. Following initial discussions on the organisation of mental health care, many of the psychiatrists who participated in regional and international conferences continued to seek out advocacy roles. In 1975, a more politically inclined Association of Psychiatrists in Africa changed its name to the Association of African Psychiatrists, reflecting both the increased number of indigenous-born psychiatrists on the continent as well as a desire for Observer status in the Organisation of African Unity (OAU). The notion of African psychiatrists having a unique perspective on the problems of mental illness in Africa was also reflected in the title of the Association's new African Journal of Psychiatry, of which Muhangi was Assistant Editor-in-Chief. ${ }^{74}$

In the longer term, however, African psychiatrists have contributed disproportionately little to research and policy within the field of international mental health. The Association of African Psychiatrists, along with its journal, collapsed in 1981 just as structural adjustment policies were starting to cripple health systems and universities, resulting in little time, funding and training for experiments or research. Reductions in travel allowances, combined with ongoing difficulties of staffing, have made it more difficult for psychiatrists to participate in conferences beyond national borders, and barriers to research and publication have resulted in relatively little research being published in international journals. While some psychiatrists continued to consult for the WHO, most did not, focusing on keeping psychiatry going within their own countries, often in difficult economic and political circumstances. Since the mid-1990s, most professional activity among psychiatrists has been limited to a regional sphere of influence. The Uganda Psychiatric Association has met for regular conferences since its formation in 1996. Psychiatrists in East Africa have met at annual scientific conferences since 1999, and a new and expanded African Association of Psychiatrists and Allied Professionals was formed in the early 2000s, starting with a meeting in Nairobi. Such activity, particularly since the early 2000s, suggests an important body of knowledge and experience that should play a central role in determining international, now global mental health policy, but which has nevertheless seen relatively little circulation outside of the continent. $^{75}$ 


\section{Notes}

1. N. Chorev, The World Health Organization Between North and South (Ithaca, 2012), p. 3

2. World Health Organization Archives (WHOA) M4/86/12(B) Jkt 1 (International Congresses of the World Federation of Mental Health), M. Pfister, 'Features and Trends in the Mental Health Work of the World Health Organization', 5 September 1961, p. 2.

3. Ibid.

4. World Health Organization, The Role of Public Health Officers and General Practitioners in Mental Health Care: Eleventh Report of the Expert Committee on Mental Health (Geneva, 1962).

5. World Health Organization, Training of Psychiatrists: Twelfth Report of the Expert Committee on Mental Health (Geneva, 1963).

6. Chorev, The World Health Organization, Ch. 3.

7. World Health Organization, Organization of Mental Health Services in Developing Countries: Sixteenth Report of the WHO Expert Committee on Mental Health (Geneva, 1975).

8. World Health Organization Library (WHOL) OMH/EC/74.11, N. Sartorius, 'Immediate Needs in Mental Health Services: A Note for Discussion', 22 October 1974, p. 1.

9. World Health Organization, Organization of Mental Health Services in Developing Countries.

10. Mental Disorders and Mental Health in Africa South of the Sahara: CCTA/CSA-WFMH-WHO Meeting of Specialists on Mental Health (Bukavu, 1958), p. 109.

11. M. M. Heaton, Black Skin, White Coats: Nigerian Psychiatrists, Decolonization, and the Globalization of Psychiatry (Ohio, 2013), p. 70.

12. G. I. Tewfik, 'Problems of Mental Illness in Uganda', in Mental Disorders and Mental Health in Africa South of the Sahara: CCTA/CSA-WFMHWHO Meeting of Specialists on Mental Health (Bukavu, 1958), p. 62.

13. T. A. Lambo, ed., First Pan-African Psychiatric Conference Report (Ibadan, 1961).

14. G. A. German and A. C. Raman, 'From Birth to Maturity-Historical Aspects of the Association of Psychiatrists in Africa', African Journal of Psychiatry 2(2) (1976), p. 258.

15. Lambo, First Pan-African Psychiatric Conference, p. 264.

16. German and Raman, 'From Birth to Maturity', pp. 255-265.

17. Personal communication with G. A. German, 29 January 2012.

18. Mental Health Services in the Developing World: Reports on Workshops on Mental Health, Edinburgh (1968) and Kampala (1969), Commonwealth Foundation Occasional Paper, IV (Hove, 1969). 
19. German and Raman, 'From Birth to Maturity', p. 258.

20. Mental Health Services in the Developing World, p. 39.

21. Ibid., p. 35.

22. Ibid., pp. 35-36.

23. Ibid., p. 38 .

24. Ibid., p. 36.

25. Ibid., p. 42.

26. Ibid.

27. Ibid.

28. G. M. Carstairs, 'Psychiatric Problems of Developing Countries', The British Journal of Psychiatry 123(574) (1973), p. 275.

29. Mental Health Services in the Developing World, p. 34.

30. WHOA NIE-HMD-002 Jkt 1 (Medical School, University of Ibadan), A. Boroffka, 'The Delivery of Mental Health Care', n.d., pp. 5-6.

31. Mental Health Services in the Developing World, p. 33.

32. Ibid., p. 34.

33. S. M. B. Diop, The Place of Mental Health in the Development of Public Health Services, Africa Regional Office (AFRO) Technical Papers no. 8 (Brazzaville, 1974), p. 32.

34. Diop, The Place of Mental Health, p. 7.

35. WHOL SEA/Ment./19 Annex 7, 'Recommendations of the International Workshop on Priorities in Mental Health Care (Held in Madurai, from 21 to 22 January 1971, under the Auspices of the World Federation for Mental Health)', p. 5.

36. WHOL OMH/EC/74.3, J. Moser, 'Approaches to the Development of Basic Mental Health Services', 1974, p. 1.

37. T. W. Harding, 'Introduction: Mental Health Services in the Developing Countries: The Issues Involved', in T. A. Baasher et al., eds., Mental Health Services in Developing Countries: Papers Presented at a WHO Seminar on the Organization of Mental Health Services, Addis Ababa, 27 November-4 December 1973 (Geneva, 1975), p. 1.

38. WHOL OMH/74.3, J. Moser, 'Development of Mental Health Services in Africa', p. 7.

39. Harding, 'Introduction: Mental Health Services in the Developing Countries', p. 2.

40. WHOL OMH/74.3, Moser, 'Development of Mental Health Services in Africa'.

41. Harding, 'Introduction: Mental Health Services in the Developing Countries'.

42. Personal communication with German; Proceedings of a Workshop on Alcohol and Drug Dependence of the Association of Psychiatrists in Africa (Nairobi, 1974). 
43. World Health Organization, Organization of Mental Health Services in Developing Countries.

44. Ibid., pp. 22-23.

45. Ibid., p. 32.

46. Ibid., p. 12 .

47. R. Giel and T. W. Harding, 'Psychiatric Priorities in Developing Countries', British Journal of Psychiatry 128(6) (1976), pp. 513-522.

48. World Health Organization, Mental Health Care in Developing Countries: A Critical Appraisal of Research Findings: Report of a WHO Study Group (Geneva, 1984), p. 5.

49. World Health Organization, Mental Health Care in Developing Countries, p. 9.

50. N. Sartorius and T. W. Harding, 'The WHO Collaborative Study on Strategies for Extending Mental Health Care, I: The Genesis of the Study', American Journal of Psychiatry 140 (1984), pp. 1470-1473.

51. World Health Organization, Mental Health Care in Developing Countries, p. 54 .

52. J. Muhangi, 'Psychiatry in Kenya: New Horizons in Medical Care', inaugural lecture delivered at the University of Nairobi, 31 January 1980.

53. Personal communication with W. Acuda, 21 October 2011.

54. Personal communication with German.

55. Personal communication with German.

56. Personal communication with Acuda.

57. D. Bhugra, 'Professor John Cox', Psychiatric Bulletin 27 (2003), p. 471; J. L. Cox, 'Cultural Psychiatry, Diversity and Political Correctness in a Shrinking World', International Psychiatry 5(2) (2008), pp. 27-28; Royal College of Psychiatrists, Report of the Working Party to Review Psychiatric Practices and Training in a Multi-Ethnic Society, Council Report CR48 (London, 1996).

58. J. Orley, 'Application of Promotion Principles', in Preventing Mental Illness: Mental Health Promotion in Primary Care (Chichester, 1998), p. 470.

59. Personal communication with German.

60. World Health Organization, The Introduction of a Mental Health Component into Primary Health Care (Geneva, 1990), p. 5.

61. Interview with V. Wankiiri (WAN-01), Kampala, 29 August 2011; WHOL AFR/MH/12, 'Training in Mental Health for Primary Health Care Workers'.

62. World Health Organization, African Mental Health Action Group, Ninth Meeting, Geneva, 9 May 1986 (Geneva, 1986), p. 18.

63. T. Baasher et al., 'On Vagrancy and Psychosis', Community Mental Health Journal 19(1) (1983), pp. 27-41; World Health Organization, Diagnostic and Management Guidelines for Mental Disorders in Primary Care: ICD-10 Chapter V Primary Care Version (Göttingen, 1996). 
64. Interview WAN-01.

65. WHOL AFR/MH/12, 'Training in Mental Health for Primary Health Care Workers', 1982.

66. [V.] B. Wankiiri, 'Problems in Achieving Mental Health for All in Southern Africa [Letter]', World Health Forum 12(2) (1991), p. 211.

67. V. B. Wankiiri, 'Delivering Mental Health Through Primary Health Care: The Lesotho Experience', Epidemiology and Community Psychiatry (Boston, 1985).

68. Wankiiri, 'Delivering Mental Health Through Primary Health Care'.

69. A.-E. Birn, 'The Stages of International (Global) Health: Histories of Success or Successes of History?' Global Public Health: An International Journal for Research, Policy and Practice 4(1) (2009), p. 58.

70. 'Declaration of Alma-Ata International Conference on Primary Health Care, Alma-Ata, USSR, 6-12 September 1978', http://www.who.int/ publications/almaata_declaration_en.pdf, last accessed 23 February 2015.

71. M. Cueto, 'The Origins of Primary Health Care and Selective Primary Health Care', American Journal of Public Health 94(11) (2004), pp. 1864-1874; O. Gish, 'Selective Primary Care: Old Wine in New Bottles', Social Science and Medicine 16(10) (1982), pp. 1049-1054; J. E. Lawn et al., 'Alma-Ata 30 Years On: Revolutionary, Relevant, and Time to Revitalise', Lancet 372(9642) (September 2008), pp. 917927; S. Litsios, 'The Long and Difficult Road to Alma-Ata: A Personal Reflection', International Journal of Health Services 32(4) (2002), pp. 709-732.

72. N. Sartorius, 'Mental Health and Primary Health Care', Mental Health in Family Medicine 5 (2008), p. 75.

73. Interview with S. Ndyanabangi (NDY-01), Ministry of Health, Kampala, 3 May 2011.

74. WHOA M4/86/25(4) (Fourth Pan African Psychiatric Congress, Abidjan, Ivory Coast, 30 June-5 July 1975), N. Sartorius, T. Harding, and J. Moser, 'Report on Attendance', n.d., p. 3.

75. O. Gureje and A. Alem, 'Hidden Science? A Glimpse at Some Work in Africa', World Psychiatry 3(3) (2004), pp. 178-181. 
Open Access This chapter is licensed under the terms of the Creative Commons Attribution 4.0 International License (http://creativecommons.org/licenses/ by $/ 4.0 /$ ), which permits use, sharing, adaptation, distribution and reproduction in any medium or format, as long as you give appropriate credit to the original author(s) and the source, provide a link to the Creative Commons license and indicate if changes were made.

The images or other third party material in this chapter are included in the chapter's Creative Commons license, unless indicated otherwise in a credit line to the material. If material is not included in the chapter's Creative Commons license and your intended use is not permitted by statutory regulation or exceeds the permitted use, you will need to obtain permission directly from the copyright holder.

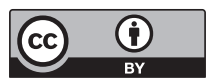

